Engineering and Computational Mechanics Volume 166 Issue EM4

Simulations of masonry-infilled reinforced concrete frame failure

Kuang and Yuen
Proceedings of the Institution of Civil Engineers

Engineering and Computational Mechanics 166 December 2013 Issue EM4 Pages 179-193 http://dx.doi.org/10.1680/eacm.13.00002

Paper 1300002

Received 02/02/2013

Published online 18/10/2013

Accepted 05/06/2013

Keywords: brickwork \& masonry/computational mechanics/concrete

structures

ICE Publishing: All rights reserved

\title{
Simulations of masonry-infilled reinforced concrete frame faillure
}

J S Kuang PhD, CEng, FICE, FIStructE

Professor, Department of Civil and Environmental Engineering, The Hong Kong University of Science and Technology, Hong Kong
Y P Yuen PhD

Research Associate, Department of Civil and Environmental Engineering, The Hong Kong University of Science and Technology, Hong Kong

In engineering practice, a competent and effective numerical tool for the comprehensive and accurate analysis of infilled frame structures subjected to different complex load patterns has not been developed. Here, a discrete method of analysis with the damage-based cohesive crack modelling technique is proposed for numerical simulations of masonry-infilled reinforced concrete frame failure. The proposed approach employs the surface-based interaction modelling technique to simulate the interfacial traction-separation behaviour, including mixed modes of fracture, crack propagation, post-fracture behaviour, and finite sliding and separation of the bonded surfaces, between contacting surfaces of masonry units. Applicability of the modelling approach for both masonry and infilled frame structures subjected to different load patterns is checked by performing computer simulations with the proposed model; the model is verified by comparing the results of experimental data. To demonstrate the wide variety of applications of the verified cohesive crack modelling technique, case studies on the non-linear behaviour of infilled frame structures under combined in-plane and out-of-plane loads and subjected to seismic excitation are conducted.

\section{Notation}

D scalar damage parameter

$f_{\text {bc }} \quad$ uniaxial compressive strength of bricks

$f_{\text {cc }} \quad$ uniaxial compressive strength of concrete

$f_{\mathrm{mc}} \quad$ uniaxial compressive strength of mortar

$f_{\mathrm{tk}} \quad$ uniaxial tensile strength of concrete

$f_{\mathrm{y}} \quad$ uniaxial yield strength of steel

$G_{\mathrm{C}} \quad$ critical strain-energy release rate

$G_{0} \quad$ strain-energy release rate at damage initiation

$G_{\mathrm{T}} \quad$ total strain-energy release rate

$\boldsymbol{k}_{\mathrm{e}} \quad$ initial isotropic elastic jump stiffness tensor

$m$ exponent in the BK law (Equation 4) for mixed-mode fracture criterion

$\boldsymbol{t}$ traction vector between two contacting surfaces

$[\boldsymbol{u}]$ displacement vector between two contacting surfaces

$W_{\mathrm{m}} \quad$ unit weight of masonry

$\beta_{\mathrm{s}} \quad$ ratio of mode II cohesion strength to tensile strength

$\beta_{\mathrm{t}} \quad$ ratio of mode III cohesion strength to tensile strength

$\phi_{\mathrm{s}} \quad$ friction angle under mode II deformation

$\phi_{\mathrm{t}} \quad$ friction angle under mode III deformation

\section{Introduction}

Numerical simulation is an effective and reliable approach to investigate the performance of infilled reinforced concrete (RC) frame structures under complex load patterns that cannot be easily realised in experiments. The non-linear finite-element method has been employed to analyse the behaviour of masonry walls and infilled frames (Hashemi and Mosalam, 2007; Kuang and Yuen, 2010; Mehrabi and Shing, 1997; Rots, 1997; Yuen and Kuang, 2012).

In infilled frames, it is well known that the interacting bracing action between infills and the bounding frame depends largely on the infill stiffness, which may degrade considerably due to damage or crack propagations under loading, as it influences the contact stress transferred at the interfaces between the two components. Hence, it is important to model the stiffness evolution or the fracture behaviour of infills suitably in order to attain reliable simulation of the structural behaviour of infilled frames. Furthermore, it is also known that infills may disintegrate and fall out of the bounding frame under out-of-plane loading, which can lead to significant change in the stress-strain distribution as well as the overall structural behaviour.

The use of conventional modelling techniques, including the use of standard continuum cohesive elements with plasticity models, often encounters difficulties in simulating these aforementioned phenomena including damage, fracture and disintegration of masonry walls. To solve this problem, a discrete modelling technique using the damage-based cohesive crack representation is first developed, with the aim of capturing the aforementioned mechanical behaviour of infilled frames. Case studies with the proposed modelling technique are performed and compared with the experimental results of masonry structures and infilled frames subjected to different loading patterns. With the well-calibrated material models, the failure mechanisms of masonry-infilled RC frames with different infill configurations under different loading patterns are then investigated.

\section{Damage-based cohesive crack representation}

To obtain accurate structural responses of masonry infills in the analysis, it is important to model properly the fracture and postfracture behaviour of mortar joints. In the literature, to model 
joint behaviour, it is common practice to use interfacial or cohesive elements of either zero or finite thickness with a frictional material type of the stress-strain behaviour following the Mohr-Coulomb criterion. In this study, a distinct modelling approach for the mortar joints is adopted. No mortar element is inserted between the masonry units, but cohesive interactions with finite sliding formulation, aiming to simulate the macroscopic traction-separation and fracture behaviour of the mortar joints, are enforced on the contact surfaces of the units.

The major advantage of the contact formulation over the use of cohesive elements is better control of element distortion and hourglass deformation modes. It can be shown that damage or inelastic deformation in masonry walls would predominantly be concentrated in the mortar joints and severe distortion of the mortar elements can be triggered, which may impair the accuracy of the simulation. Thus, the contact formulation is a more effective tool to simulate extensive crack opening and propagation behaviour as well as component disintegration in infills.

In addition, the contact discretisation used is known as the 'surface-surface discretisation' method. In contrast with the traditional 'node-surface discretisation', in which the contact tracking and interaction between contacting surfaces are enforced at individual nodes on slave surfaces, the surface-surface discretisation method enforces contact conditions averaging over the regions approximately centred at slave nodes (Abaqus, 2010). The major advantages of surface-surface discretisation over node-surface discretisation are better tracking of global contact conditions, possible global penetration of master surfaces into slave surfaces and higher accuracy.

\subsection{Formulation of the traction-separation law}

Due to the masonry units' restraint, macroscopic cracks, which inflict macroscopic stiffness degradation, are eventually aligned with the bed planes regardless of the fracture modes. Consideration of this sole macroscopic damage mechanism and typical structural actions, in-plane normal and shear deformations would be experienced by mortar joints in realistic masonry structures. It is thus sufficient to use a damage variable to model the stiffness degradation effect due to the formation of cracks in mortar joints. The traction-separation law for cohesive cracks considering the mixed-mode fracture behaviour of the mortar joints is

\section{1. $\boldsymbol{t}=(1-D) \boldsymbol{k}_{\mathrm{e}}[\boldsymbol{u}]$}

where $\boldsymbol{t}$ and $[\boldsymbol{u}]$ are the traction and displacement jump vectors between two masonry unit surfaces, respectively, $\boldsymbol{k}_{\mathrm{e}}$ is an initial isotropic elastic stiffness tensor and $D$ is a scalar damage parameter of value within $[0,1]$ and taken as 0 under compressive normal traction to account for the unilateral effect. The criterion of damage initiation is defined as
2. $t_{\mathrm{n}}^{2}+\beta_{\mathrm{s}}^{2} t_{\mathrm{s}}^{2}+\beta_{\mathrm{t}}^{2} t_{\mathrm{t}}^{2}-f_{\mathrm{nt}}^{2}=0 \quad\left(t_{\mathrm{n}} \geqslant 0\right)$

$$
\beta_{\mathrm{s}}^{2}\left(\left|t_{\mathrm{s}}\right|+t_{\mathrm{n}} \tan \phi_{\mathrm{s}}\right)^{2}+\beta_{\mathrm{t}}^{2}\left(\left|t_{\mathrm{t}}\right|+t_{\mathrm{n}} \tan \phi_{\mathrm{t}}\right)^{2}-f_{\mathrm{nt}}^{2}=0
$$

3. $\left(t_{\mathrm{n}}<0\right)$

where $f_{\mathrm{nt}}$ is the tensile strength of the mortar joints, $\beta_{\mathrm{s}}$ and $\beta_{\mathrm{t}}$ are the ratios of mode II shear cohesion strength and mode III tear cohesion strength to the tensile strength, respectively, and $\phi_{\mathrm{s}}$ and $\phi_{\mathrm{t}}$ are the friction angles under mode II and mode III deformation, respectively. It is assumed that the critical strain-energy release rate $G_{\mathrm{C}}$ under mixed-mode fracture is represented by the BK law (Benzeggagh and Kenane, 1996)

4. $G_{\mathrm{C}}=G_{\mathrm{IC}}+\left(G_{\mathrm{IIC}}+G_{\mathrm{IIIC}}-G_{\mathrm{IC}}\right)\left(\frac{G_{\mathrm{IIC}}+G_{\mathrm{IICC}}}{G_{\mathrm{T}}}\right)^{m}$

and the evolution of damage is assumed to have the form

5. $D=\frac{G_{\mathrm{T}}([\boldsymbol{u}])-G_{0}}{G_{\mathrm{C}}-G_{0}}$

where $G_{\mathrm{IC}}, G_{\mathrm{IIC}}$ and $G_{\mathrm{IIIC}}$ are critical strain-energy release rates under pure mode I, pure mode II and mode III fracture, respectively, $m$ is an exponent that depends on the brittleness of the material, $G_{0}$ is the strain-energy release rate at damage initiation and $G_{\mathrm{T}}$ is the total strain-energy release rate defined as

$$
\begin{aligned}
G_{\mathrm{T}}([\boldsymbol{u}])= & \int\left\{t_{\mathrm{n}}\right\} \mathrm{d}\left[u_{\mathrm{n}}\right]+\int\left(\left|t_{\mathrm{s}}\right|-\left\{-t_{\mathrm{n}}\right\} \tan \phi_{\mathrm{s}}\right) \mathrm{d}\left[u_{\mathrm{s}}\right] \\
& +\int\left(\left|t_{\mathrm{t}}\right|-\left\{-t_{\mathrm{n}}\right\} \tan \phi_{\mathrm{t}}\right) \mathrm{d}\left[u_{\mathrm{t}}\right]
\end{aligned}
$$

where $\{\cdot\}$ denotes the Macaulay bracket: $\{a\}=a$ if $a \geqslant 0$ and $\{a\}=0$ otherwise.

When the contact surfaces are under compression, the joints behave similarly to Mohr-Coulomb materials and crack propagation is governed by mode II fracture. Yet, when the surfaces are subjected to interacting tension and shear, a mixed-mode fracture criterion of $\mathrm{BK}$ form would control crack propagation. Once mortar joints are fractured, $D=1$, and the post-cracking interaction property of the two contact surfaces follows the Coulomb friction law, the slip criterion is defined as

7. $f=\left(\left|t_{\mathrm{s}}\right|-\left\{-t_{\mathrm{n}}\right\} \tan \phi_{\mathrm{s}}\right)^{2}+\left(\left|t_{\mathrm{t}}\right|-\left\{-t_{\mathrm{n}}\right\} \tan \phi_{\mathrm{t}}\right)^{2}=0$ 
The model was implemented in Abaqus through the user subroutine VUinteraction for the traction-separation behaviour in general contact simulations. The integration scheme used for the model is based on a standard, modified explicit Euler scheme with sub-stepping; description of the algorithms is presented by Sloan et al. (2001) and details of the numerical implementation of the model have been given by Yuen (2012). The cohesive cracking behaviour of mortar joints under single and mixed modes of loading is shown in Figure 1.

For brittle or quasi-brittle materials, cracks are initiated and their propagation is driven by tension, hence mode I fracture, and so it is apparent that cracks cannot propagate under pure mode II or mode III action. However, shear fracture and crack propagation in mode II of concrete and mortar at the macroscopic scale has been reported and discussed (Bažant and Pfeiffer, 1986; Davies, 1995). Under mode II action, microscopic inclined tensile cracks are formed and later joined together by shear, resulting in macroscopic shear fracture (Bažant and Pfeiffer, 1986). Hence, the mode I or mode III fracture energy presented here is not the energy breaking microscopic bonds in a lattice but the macroscopically averaged energy, minus the frictional dissipation when

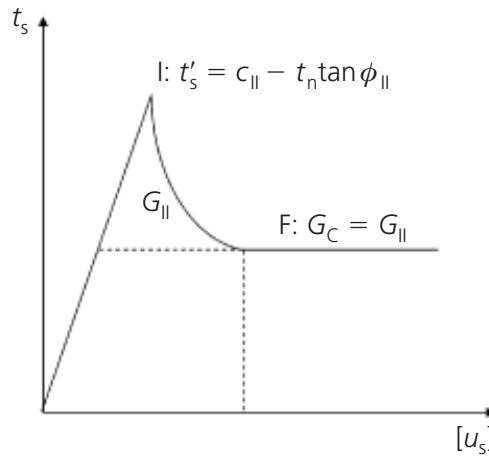

(a)

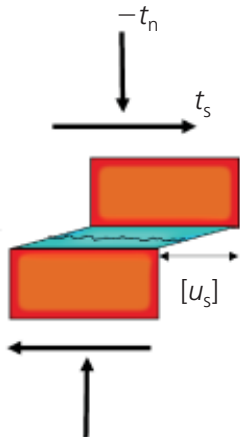

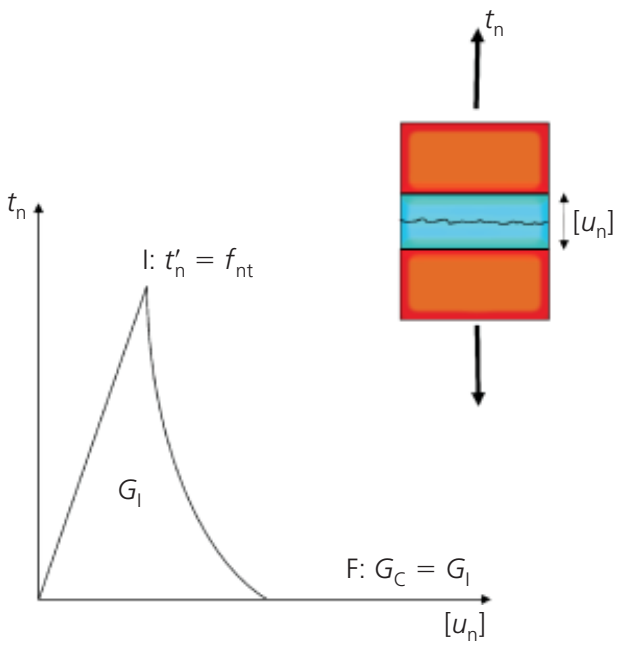

(b)
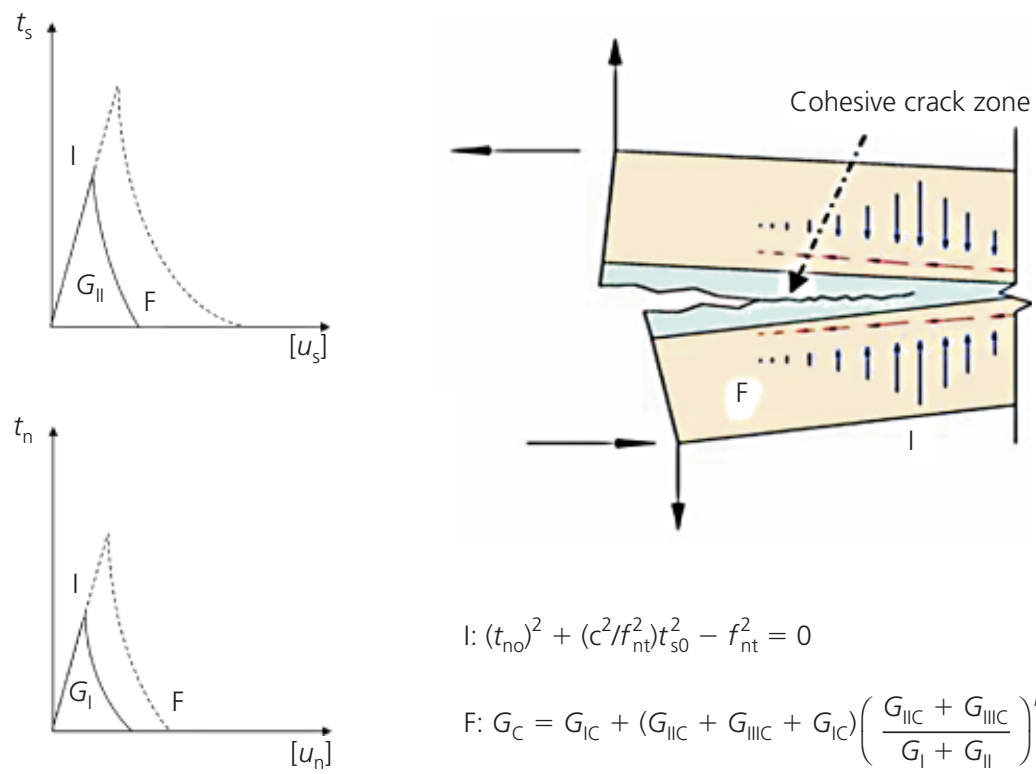

$$
\begin{aligned}
& \text { I: }\left(t_{\mathrm{no}}\right)^{2}+\left(\mathrm{c}^{2} / f_{\mathrm{nt}}^{2}\right) t_{\mathrm{s0}}^{2}-f_{\mathrm{nt}}^{2}=0 \\
& \text { F: } G_{\mathrm{C}}=G_{\mathrm{IC}}+\left(G_{\| C}+G_{\| I C}+G_{I C}\right)\left(\frac{G_{\| C}+G_{\| C}}{G_{I}+G_{\|}}\right)^{m}
\end{aligned}
$$

(c)

Figure 1. Fracture behaviour of mortar joints. (a) Mode II fracture (under compression). (b) Mode I fracture. (c) Mixed mode I and mode II fracture 
under normal compression, required for shearing masonry composites to failure or fracture states.

Furthermore, the proposed traction-separation law assumes nondilative flow and constant friction angle and then does not consider the dilatation and possible degradation of the friction angle of materials under cyclic loading. These assumptions are based on the experimental study on the shear behaviour of mortar joints by Van der Pluijm (1993). These test results showed that the dilatation angle of mortar is very small under shear deformation (less than $10^{\circ}$ ) and the residual friction angle remains nearly constant under cyclic loading due to the smooth fractured surfaces suffering little damage and loss of asperities. Hence, the assumption of non-dilative flow and constant friction angle has been widely adopted in the analysis of masonry structures (Rots, 1997).

\subsection{Verification of the modelling technique}

To testify the applicability of the modelling technique for masonry walls under both in-plane and out-of-plane loading conditions, simulations were carried out for two experiments an in-plane lateral shear test on a masonry pier (Raijmakers and Vermltfoort, 1992) and an out-of-plane loading test on a masonry-infilled frame (Angel et al., 1994).

Two identical tests, labelled as J4D and J5D (Raijmakers and Vermltfoort, 1992), were selected to verify the correctness of the in-plane behaviour simulated by the modelling method. The model parameters adopted in this verification study include, for bricks, Young's modulus $=15 \mathrm{GPa}$ and Poisson's ratio $=0 \cdot 15$. For the mortar joints, Young's modulus $=1.5 \mathrm{GPa}$, Poisson's ratio $=0 \cdot 13$, tensile strength $f_{\text {nt }}=0.3 \mathrm{MPa}$, shear and tear cohesion $c_{\mathrm{s}}=c_{\mathrm{t}}=0.6 \mathrm{MPa}$, friction angles $\phi_{\mathrm{s}}$ and $\phi_{\mathrm{t}}=30^{\circ}$, critical strain-energy release rate $G_{\mathrm{IC}}=15 \mathrm{~J} / \mathrm{m}^{2}$ for mode $\mathrm{I}$ and $G_{\text {IIC }}=35 \mathrm{~J} / \mathrm{m}^{2}$ for mode II, and exponent of the BK law $m=2 \cdot 2$. The crack patterns of specimens J4D and J5D and the computational model are shown in Figures 2(a)-2(d); Figure 2(e) shows the load-deflection curves obtained from the simulation plotted together with the experimental curves.

To verify the out-of-plane behaviour predicted by the model, a computer simulation was performed for an out-of-plane loading test on specimen \#1 from the experimental work of Angel et al. (1994). The model parameters adopted for bricks are Young's modulus $=11.4 \mathrm{GPa}$, Poisson's ratio $=0 \cdot 15$ and compressive strength $=24 \mathrm{MPa}$. For the mortar joints, Young's modulus = $1.52 \mathrm{GPa}$, Poisson's ratio $=0 \cdot 13$, tensile strength $f_{\text {nt }}=0.28 \mathrm{MPa}$, shear and tear cohesion $c_{\mathrm{s}}=c_{\mathrm{t}}=0.62 \mathrm{MPa}$, friction angles $\phi_{\mathrm{s}}$ and $\phi_{\mathrm{t}}=30^{\circ}$, critical strain-energy release rate $G_{\mathrm{IC}}=$ $17.5 \mathrm{~J} / \mathrm{m}^{2}$ for mode I and $G_{\text {IIC }}=35 \mathrm{~J} / \mathrm{m}^{2}$ for mode II, and the exponent of the BK law $m=2 \cdot 2$. The crack pattern of the test specimen and the computational model are shown in Figures $3(a)-3(c)$ and the load-deflection curves obtained from the simulation are plotted together with the experimental curves in Figure 3(d).
Figure 2 and Figure 3 indicate that the simulation performed with the proposed modelling method agrees well with experimental results from both in-plane and out-of-plane loading tests.

\section{Local infill-frame interaction and damage mechanisms}

Use of the proposed discrete cohesive crack modelling technique and its capability in simulating various structural phenomena are demonstrated by a study of the local behaviour of the infill-frame interaction. The in-plane behaviour of unreinforced masonry infilled frames has been studied extensively (Crisafulli and Carr, 2007; Hashemi and Mosalam, 2007; Moghaddam and Dowling, 1987). However, few studies have been conducted on the behaviour of infilled RC frames under the combined action of in-plane and out-of-plane loads, even though this is a very common situation in realistic three-dimensional (3D) buildings.

This study thus aimed to investigate the failure mechanisms and force transfer mechanisms of RC frames infilled with masonry infills of different anchorage conditions and different configurations based on rigorous computational simulation. The selected prototype model is based on part of a realistic and typical infilled $\mathrm{RC}$ frame building. The structural performance of RC frames with full-height infills and infills with a door opening, under four sets of combined in-plane and out-of-plane loads, are studied by pushover analysis. The local infill-frame interaction is particularly emphasised in the analyses.

\subsection{Prototype structures and discrete finite-element modelling}

The prototype of a one-bay, one-storey RC frame shown in Figure 4 was used for the investigation. This is part of a typical RC frame building, designed to resist seismic loads with peak ground acceleration (PGA) of $0 \cdot 15 \mathrm{~g}$, where the frame members are detailed to achieve moderate ductility with an expected displacement ductility factor of between 2 and 4 . The 115-mm-thick infill walls are composed of $240 \times 115 \times 90 \mathrm{~mm}$ solid masonry bricks.

Two typical infill configurations were studied: full-height infills and infills with a door opening of $1050 \times 2100 \mathrm{~mm}$. The compressive strength of the concrete was $20 \cdot 1 \mathrm{MPa}$ and the yield strengths of the longitudinal and transverse reinforcement were $400 \mathrm{MPa}$ and $235 \mathrm{MPa}$, respectively. The compressive strengths of $240 \times 115 \times 90 \mathrm{~mm}$ bricks and 10 -mm-thick mortar joints were $15 \mathrm{MPa}$ and $5 \mathrm{MPa}$, respectively.

Discrete finite-element models for the prototype infilled RC frames were developed using Abaqus with a user subroutine to define the cohesive crack behaviour. All components of the structures were modelled as distinct elements with well-calibrated non-linear constitutive laws, and their mutual interactions were simulated using appropriate constraints or contact properties. The concrete frame was discretised into linear eight-node 3D solid 


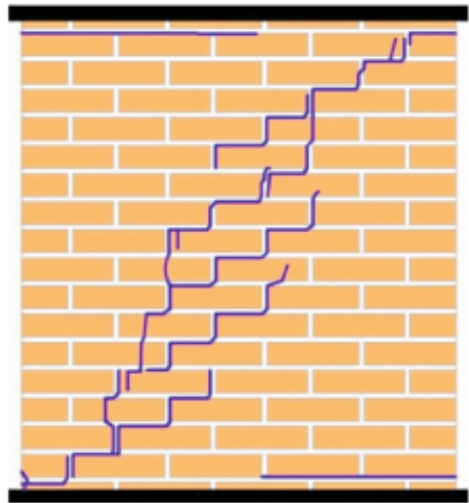

(a)

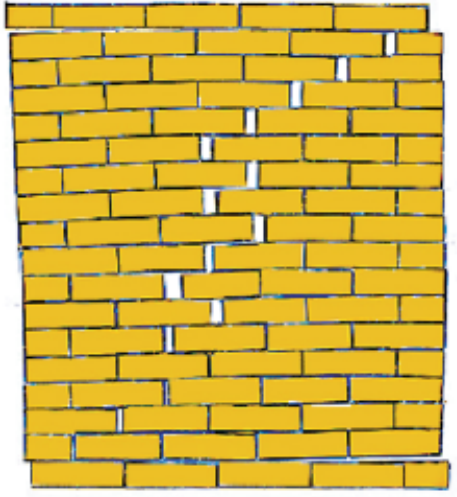

(c)

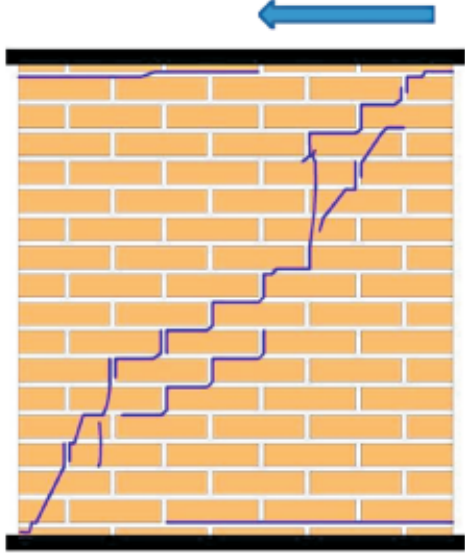

(b)

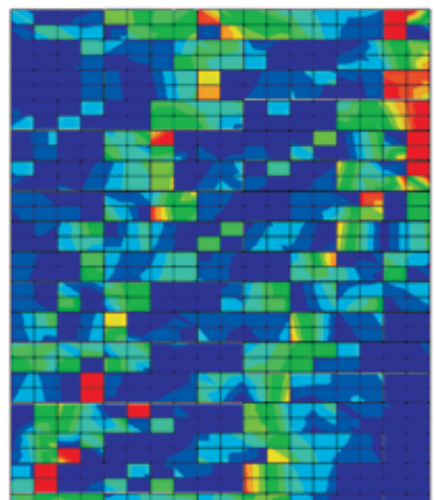

S, Min. Principal (Avg: $75 \%$ )

$+0.000 \mathrm{e}+00$

$-1.667 \mathrm{e}-0$

$-5.000 \mathrm{e}-01$

$-6.667 \mathrm{e}-01$

$-8.333 \mathrm{e}-01$

$-1.000 \mathrm{e}+00$

$-1.333 \mathrm{e}+00$

$-1.500 \mathrm{e}+00$

$1.667 \mathrm{e}+00$

$1.833 \mathrm{e}+00$

$-2.000 \mathrm{e}+00$

(d)

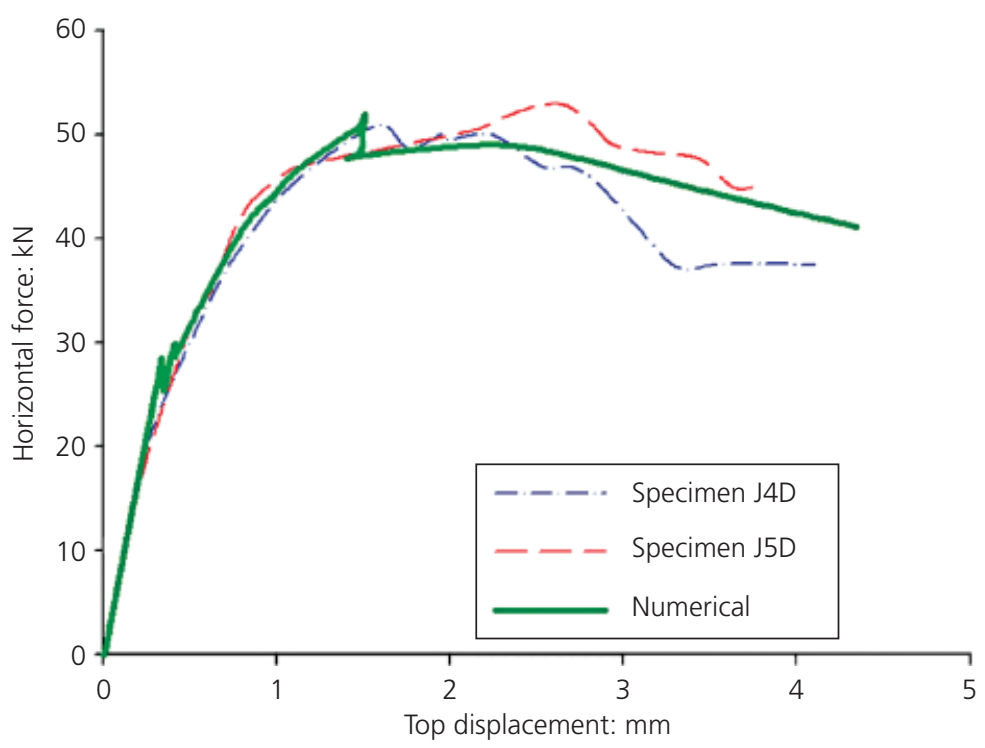

(e)

Figure 2. Comparison of experimental (Raijmakers and

Vermltfoort, 1992) and numerical results. (a) Crack pattern of specimen J4D. (b) Crack pattern of specimen J5D. (c) Simulated crack pattern (top drift $=3 \mathrm{~mm}$ ). (d) Principal compressive stress distribution after major cracking (top drift $=3 \mathrm{~mm}$ ).

(e) Horizontal load-displacement curves 


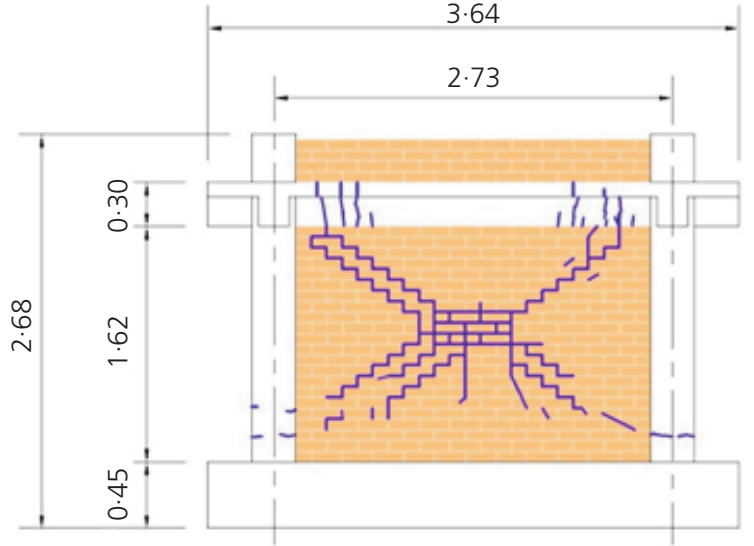

(a)

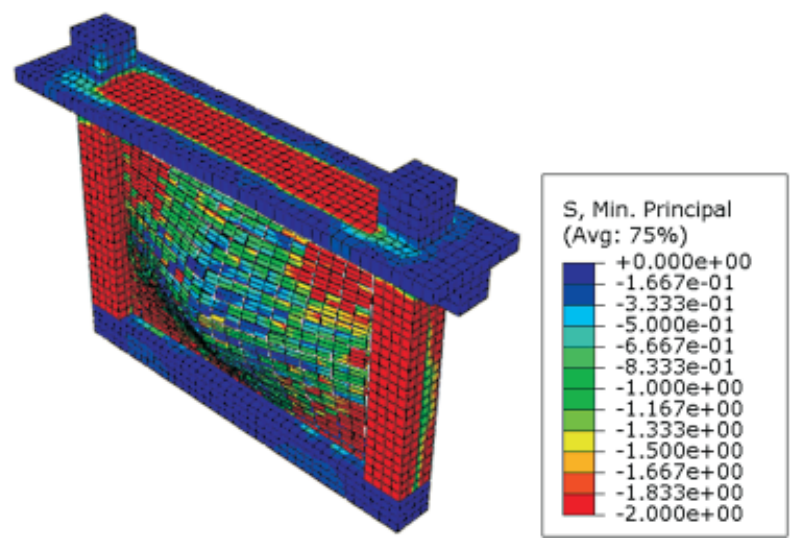

(c)

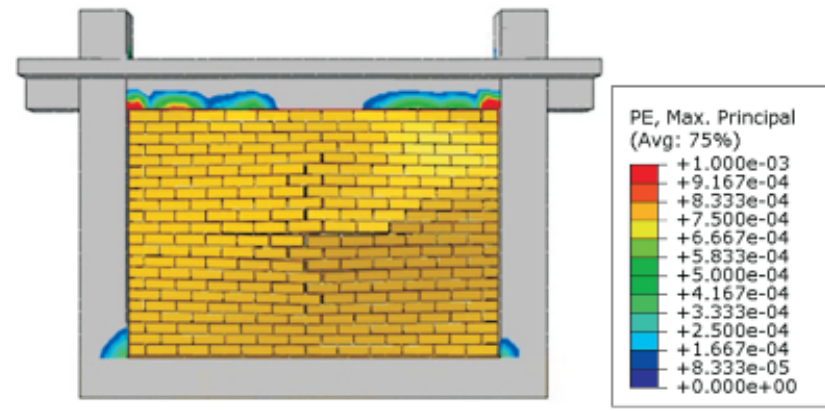

(b)

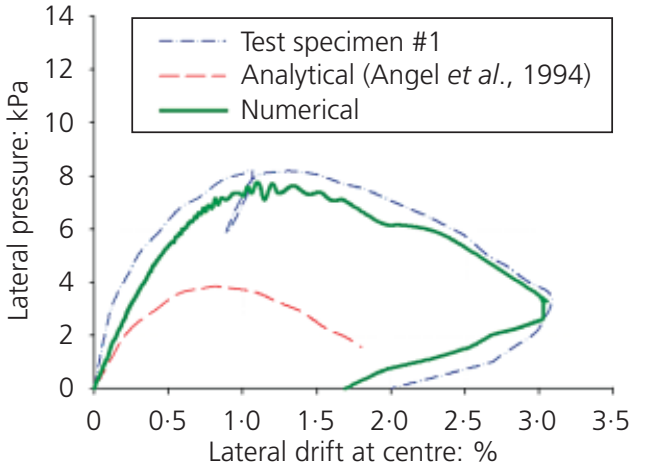

(d)

Figure 3. Comparison of experimental (Angel et al., 1994) and numerical results. (a) Crack pattern of specimen \#1 (dimensions in m). (b) Simulated crack pattern and deformation (exaggerated 10 times). (c) Principal compressive stress distribution after cracking. (d) Lateral pressure-displacement curves

elements and its mechanical behaviour was modelled with the smeared isotropic damage-plasticity model (Lubliner et al., 1989). The steel reinforcement was modelled with a two-node 3D truss element (T3D2) and the smeared stress-strain curve for embedded reinforcement was used to present the constitutive relationship (Hsu and Mansour, 2005). To model the crack propagation in the infills, the discrete damage-based cohesive interaction was enforced on the contacting surfaces of the masonry units, as discussed earlier. Progressive refinement of meshing size was conducted to obtain convergent results of the analysis.

The material properties adopted for the infills of the prototype structure were as follows. For the bricks, Young's modulus $=23 \mathrm{G}-$ $\mathrm{Pa}$, Poisson's ratio $=0 \cdot 15$, peak tensile strength $=2 \mathrm{MPa}$ and critical crack displacement $=0.025 \mathrm{~mm}$. For the mortar joints, Young's modulus $=1.5 \mathrm{GPa}$, Poisson's ratio $=0.13$, tensile strength $f_{\text {nt }}=0.3 \mathrm{MPa}$, shear and tear cohesion $c_{\mathrm{s}}=c_{\mathrm{t}}=0.7 \mathrm{MPa}$, friction angles $\phi_{\mathrm{s}}$ and $\phi_{\mathrm{t}}=30^{\circ}$, critical strain-energy release rate $G_{\mathrm{IC}}=15 \mathrm{~J} / \mathrm{m}^{2}$ for mode I and $G_{\mathrm{IIC}}=G_{\mathrm{IIIC}}=35 \mathrm{~J} / \mathrm{m}^{2}$ for modes II and III, and the exponent of the BK law $m=2 \cdot 2$.

\subsection{Results and discussion}

In each of the three infilled RC frame prototype structures (full infills (F) and infills with door opening (D)), four cases of pushover analysis were considered where the infills were subjected to four levels of out-of-plane body forces: 0, 10, 20 and $40 \mathrm{kN} / \mathrm{m}^{3}$. The pushover curves of the frames (plots of base shear against lateral displacement) under different levels of the prescribed out-of-plane loads are shown in Figure 5.

Table 1 summarises the stiffness, cracking strengths, peak strengths and the corresponding storey drifts of the frames obtained from the analyses. The detailed behaviours of each frame under pure in-plane loading or combined in-plane and outof-plane loads are now discussed separately. 


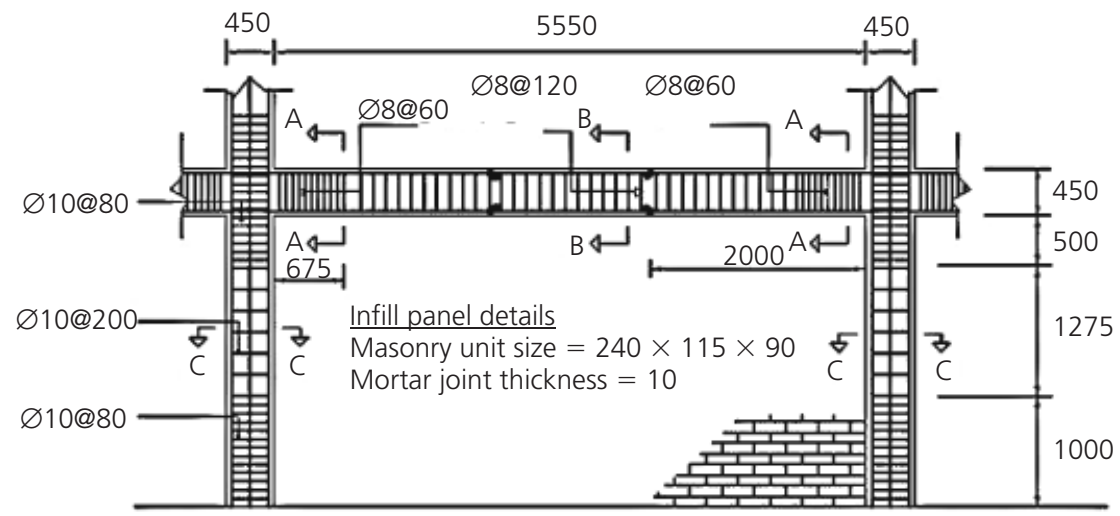

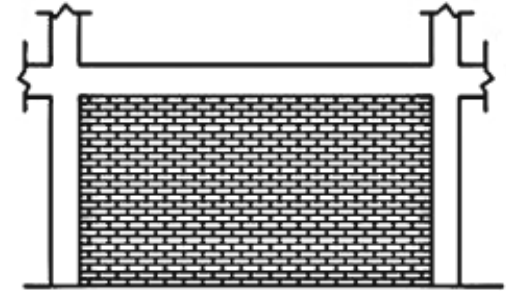

Full-height infill panel

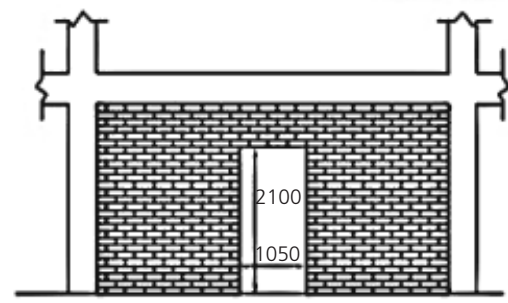

Full-height infill panel with door opening

Figure 4. Dimensions and reinforcement details of the prototype structures (dimension in $\mathrm{mm}$ )
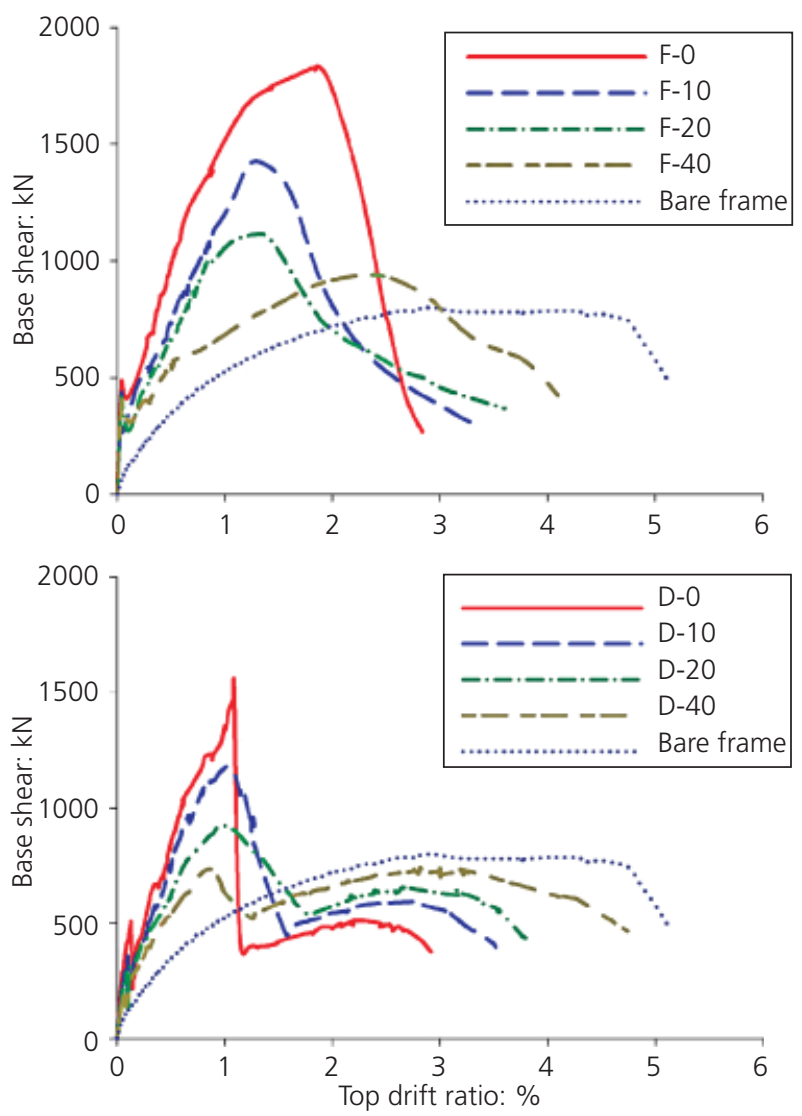

Figure 5. Pushover curves of infilled RC frames under combined in-plane and out-of-plane loads

\subsubsection{In-plane behaviour}

The evolution of damage and stress transfer mechanisms in the infilled frame structures is shown in Figure 6. The laterally loaded bare frame fails in a typical ductile mode, where plastic hinges are first formed at the end of members; crushing of the concrete at hinges then occurs, followed by buckling of the steel reinforcement in column, as shown in Figure $6(\mathrm{~b})$. The bare frame has a yield displacement of $1 \cdot 30 \%$ at $75 \%$ of the ultimate strength and an ultimate displacement of $4 \cdot 80 \%$ where the residual strength reduced by $20 \%$ of the peak strength. Therefore, the bare frame has a displacement ductility factor of 3.69 , which is consistent with the expectation that the frame would have moderate ductility (between 2 and 4).

As shown in Table 1, the initial stiffness of the fully infilled frame is almost 7.5 times larger than that of the bare frame. However, the peak strength has only increased by about $2 \cdot 3$ times and the displacement ductility factor is even decreased by $35 \%$ to $2 \cdot 41$. In contrast to the bare frame, damage of the bounding frame is localised at the braced corners (Figures 6(c) and $6(d)$ ), while rotation of the plastic hinges in the beam is restrained by the infill wall and suffers only little damage. Consequently, the capacity design philosophy (Park, 1989; Paulay and Priestley, 1992) or the weak beam/strong column design of frame structures cannot be achieved.

Furthermore, it can be noticed that the lateral load is smoothly transferred through the full infills from the loading corner to the opposing corner before cracking occurs. However, once major sliding cracks occur and cut through infills, the stress field 


\begin{tabular}{|c|c|c|c|c|c|c|}
\hline Model frame ${ }^{a}$ & $\begin{array}{l}\text { Crack initiation } \\
\text { load: } k N^{b}\end{array}$ & $\begin{array}{l}\text { Lateral drift at } \\
\text { crack: } \% h_{s}^{c}\end{array}$ & $\begin{array}{l}\text { Peak in-plane } \\
\text { load: kN }\end{array}$ & $\begin{array}{c}\text { Lateral drift at } \\
\text { peak: } \% h_{\mathrm{s}}\end{array}$ & $\begin{array}{l}\text { Initial stiffness: } \\
\text { kN/mm }\end{array}$ & $\begin{array}{c}\text { Secant stiffness at } \\
\text { peak: } \mathrm{kN} / \mathrm{mm}\end{array}$ \\
\hline Bare frame & - & - & $799 \cdot 2$ & $3 \cdot 16$ & 48.84 & 8.43 \\
\hline $\mathrm{F}-\mathrm{O}$ & $485 \cdot 4$ & 0.044 & $1823 \cdot 1$ & $1 \cdot 8$ & 363.94 & $33 \cdot 76$ \\
\hline $\mathrm{F}-10$ & $423 \cdot 5$ & 0.040 & $1427 \cdot 4$ & $1 \cdot 56$ & 352.92 & $30 \cdot 50$ \\
\hline $\mathrm{F}-20$ & $400 \cdot 3$ & 0.042 & $1112 \cdot 5$ & $1 \cdot 37$ & $317 \cdot 70$ & $27 \cdot 07$ \\
\hline$F-40$ & $390 \cdot 9$ & 0.050 & 938.4 & $2 \cdot 42$ & $260 \cdot 60$ & $12 \cdot 93$ \\
\hline D-0 & $482 \cdot 3$ & 0.135 & $1473 \cdot 5$ & 1.08 & 119.09 & $45 \cdot 48$ \\
\hline D-10 & 333.9 & 0.101 & $1180 \cdot 2$ & 1.04 & $110 \cdot 19$ & 37.83 \\
\hline D-20 & $277 \cdot 8$ & 0.092 & 921.8 & 0.96 & $100 \cdot 65$ & 32.01 \\
\hline$D-40$ & 194.9 & 0.079 & 733.6 & 0.88 & $82 \cdot 22$ & $27 \cdot 79$ \\
\hline
\end{tabular}

${ }^{a} F$, full infill; $D$, infill with door opening; the number denotes magnitude of out-of-plane body force $\left(0,10,20\right.$ and $\left.40 \mathrm{kN} / \mathrm{m}^{3}\right)$

$\mathrm{b}$ Load at which major crack formation occurred in infills

${ }^{\mathrm{c}} h_{\mathrm{s}}$ is storey height $(3 \mathrm{~m})$

Table 1. Cracking strengths, peak base shears and corresponding drifts of model frames

becomes complicated and a dominating strut forms again, bracing the loading corners to a nearby portion of the ground beam.

The stiffness and strength of the infilled frame with door opening are again enhanced significantly, yet weaker than the full infill models; initial stiffness and peak strength are 2.44 and 1.84 times larger than those of the bare frame, respectively. The frame with door opening also exhibits similar localised damage behaviour, as shown in Figures 6(e) and 6(f). On the other hand, a very distinct feature in the pushover curve of the door-opening infilled frame is noticed, as shown in Figure 5(b), where the post-peak strength drops dramatically but is followed by a long tail curve where the strength gradually increases to a local peak and then declines again. This is because of the collapse of the infills at peak and afterwards the lateral load is mainly resisted by the damaged bare frame. For full infills that are continuous and well confined by the bounding frame, such collapse is not possible without any out-of-plane action and therefore such a drop and tail are not observed as the drop in strength is simply due to shear damage of the braced corners.

\subsubsection{Influence of out-of-plane action}

Under the influence of out-of-plane action, the bracing action provided by the infills becomes weaker and both the stiffness and strength of the structures decline with higher prescribed out-ofplane loads. Figure 7 shows the reductions in stiffness and strength under different out-of-plane loads, where the stiffness or strength is normalised by the values at zero out-of-plane loads. In spite of the weak bracing action, the lateral load transferring mechanisms under prescribed out-of-plane loads usually do not deviate too much from those under no out-of-plane loads. As shown in Figure 7, under the influence of out-of-plane loads, there is some reduction in secant stiffness and peak strength from $10 \%$ and $20 \%\left(0 \cdot 5 W_{\mathrm{m}}\right)$ to as much as $60 \%$ and $50 \%\left(2 W_{\mathrm{m}}\right)$ accordingly as compared to that when the fully infilled frame is subjected to pure in-plane loading, where $W_{\mathrm{m}}$ is the unit weight of the masonry. There is a noticeable change in the characteristics or the shape of the pushover curve when the frame is subjected to an out-of-plane load of $2 W_{\mathrm{m}}$. This change is due to the fact that, at a low level of prescribed out-of-plane loading, the loaddeformation behaviour of the frame is governed by shear damage of the braced column. However, at a higher level of out-of-plane loading, say $2 W_{\mathrm{m}}$, large central segments of the infills fall apart during in-plane loading, as shown in Figure 8(a), and this collapse of infills governs the global load-deformation behaviour.

As shown in Figure 5(b), the influence of out-of-plane loads on the in-plane load-deflection behaviour of the door-opening infilled frame shows a consistent and gradual trend. The degradation rate in cracking strength is the faster of the two configurations. This is due to the fact that cracking at the stress concentration zone around the opening is promoted by out-ofplane loading, while the peak-strength degradation behaviour is quite similar to the fully infilled frame since the post-cracking load transfer mechanisms before the peak of the two infilled frames are similar, as shown in Figure 8(b).

\section{Dynamic response and seismic performance}

In addition to the non-linear static analysis with the proposed cohesive crack modelling technique as presented in Section 3, the technique is also applicable in non-linear dynamic analysis. The major cause of vulnerability to earthquakes of infilled structures is due to neglect of the effect of infills on the overall performance of the structure since, in conventional design practice, infill walls of a building frame are normally considered non-structural members. However, it has been clearly demonstrated in the previous nonlinear static analysis that the presence of infill walls can significantly alter the structural performance. It is conceivable that, owing to the brittle nature of infill materials, even more severe adverse effect of infills on the structures can be incurred under 
Engineering and Computational Mechanics Volume 166 Issue EM4
Simulations of masonry-infilled reinforced concrete frame failure

Kuang and Yuen

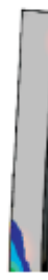
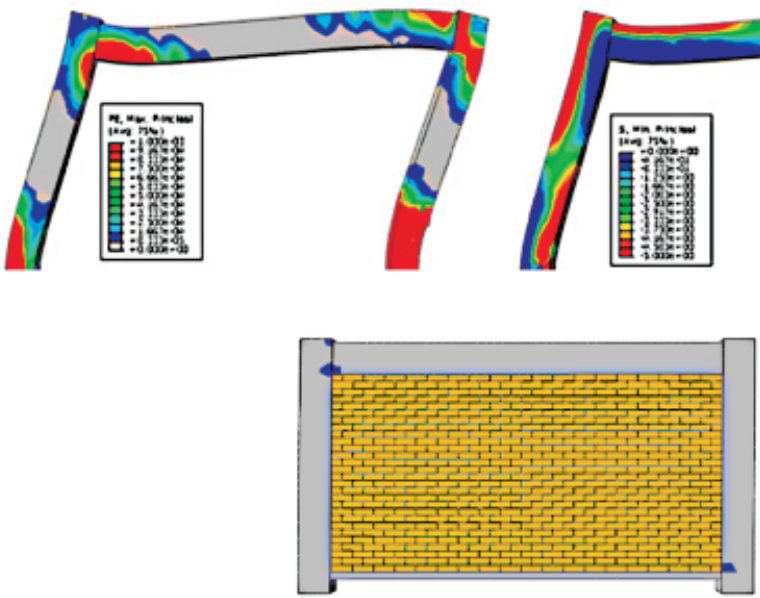

(b)
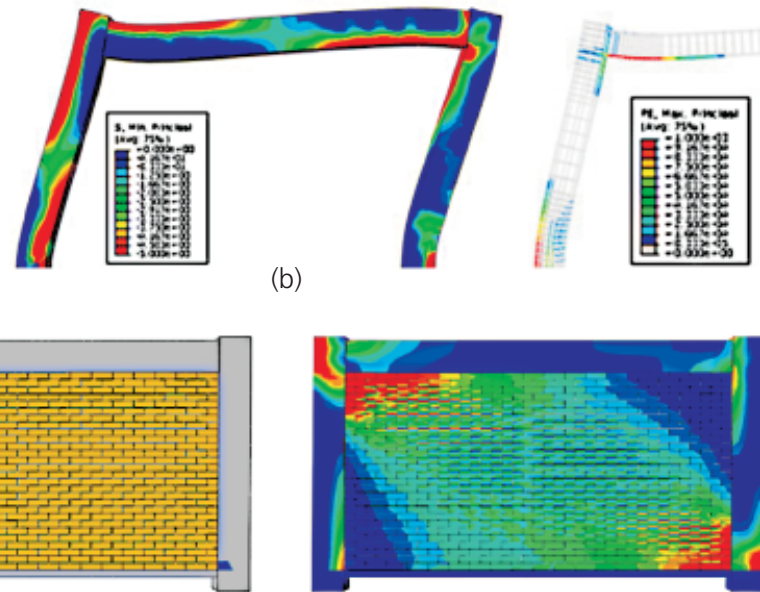

(c)
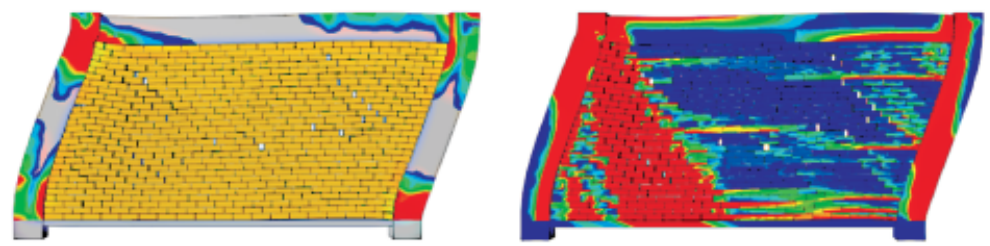

(d)
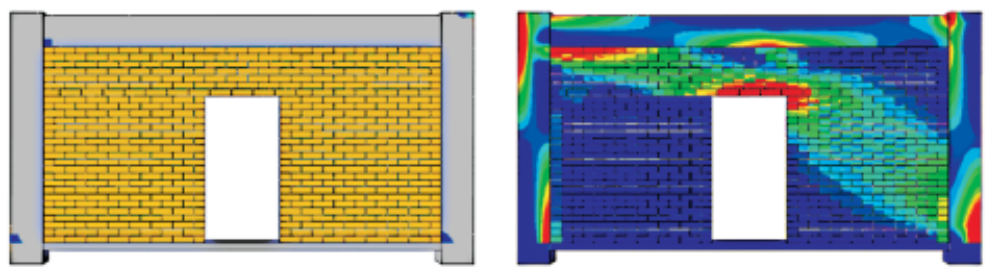

(e)
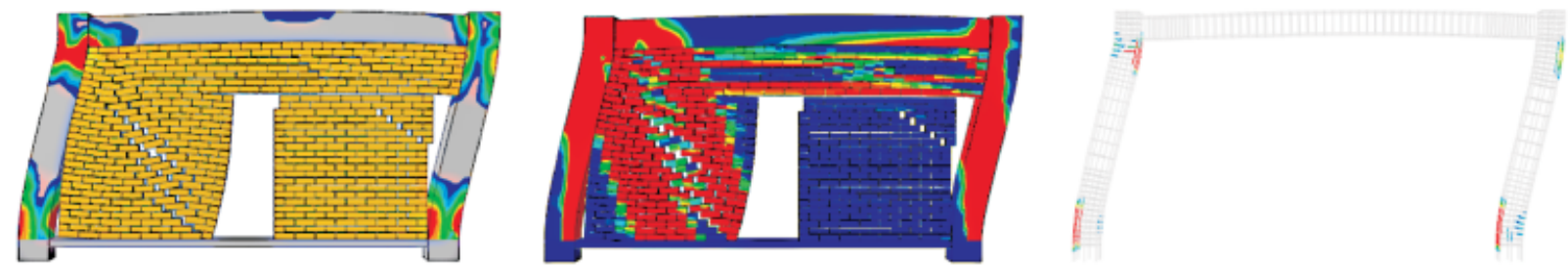

(f)

Figure 6. Evolution of damage and stress transfer mechanisms in infilled frame structures. (a) Bare frame, drift ratio $=1 \%$. (b) Bare frame, drift ratio $=4 \cdot 5 \%$. (c) Fully infilled frame, drift ratio $=0.05 \%$. (d) Fully infilled frame, drift ratio $=1.5 \%$.

(e) Infilled frame with door opening, drift ratio $=0.05 \%$.

(f) Infilled frame with door opening, drift ratio $=1 \%$. 

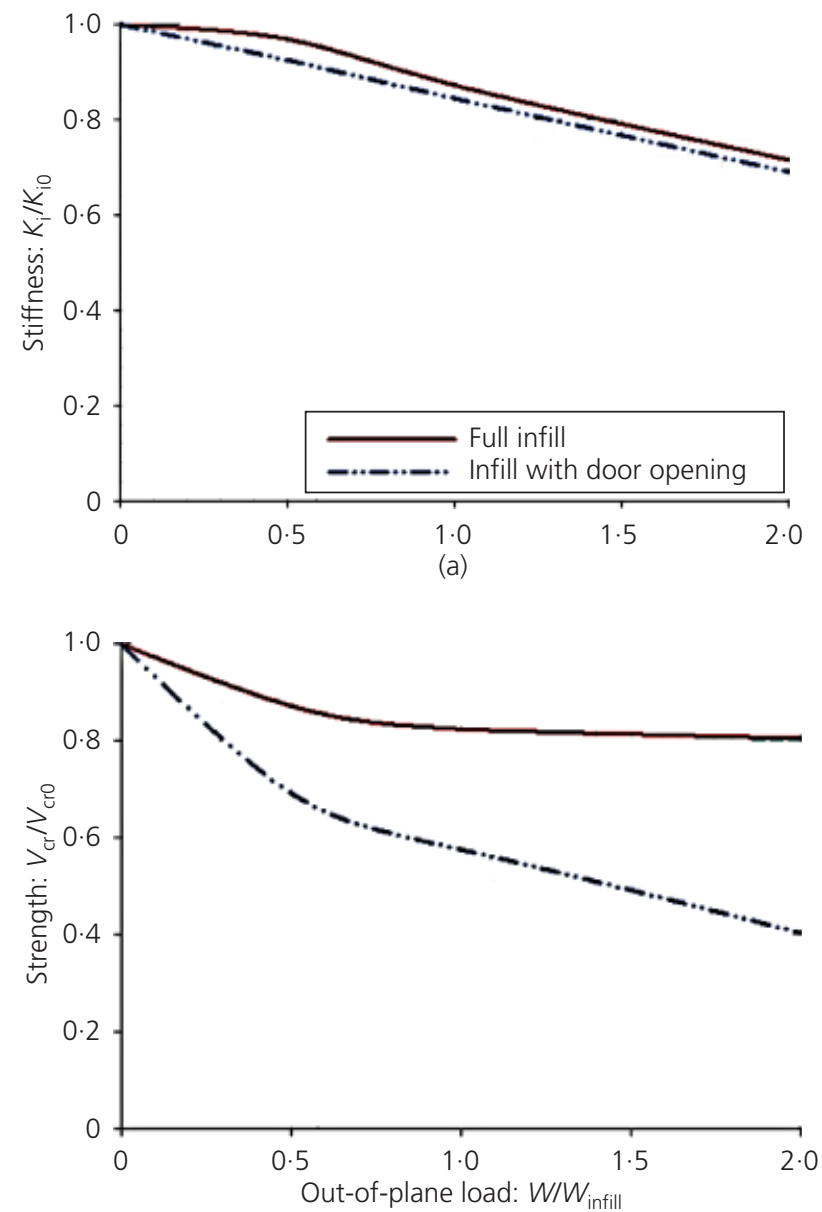

(c)

Figure 7. Influence of out-of-plane loads on (a) initial stiffness $K_{\mathrm{i}}$,

(b) secant stiffness at peak $K_{\mathrm{s}}$, (c) cracking strength $V_{\text {cr }}$ and

(d) peak strength $V_{p}$ of infilled frames
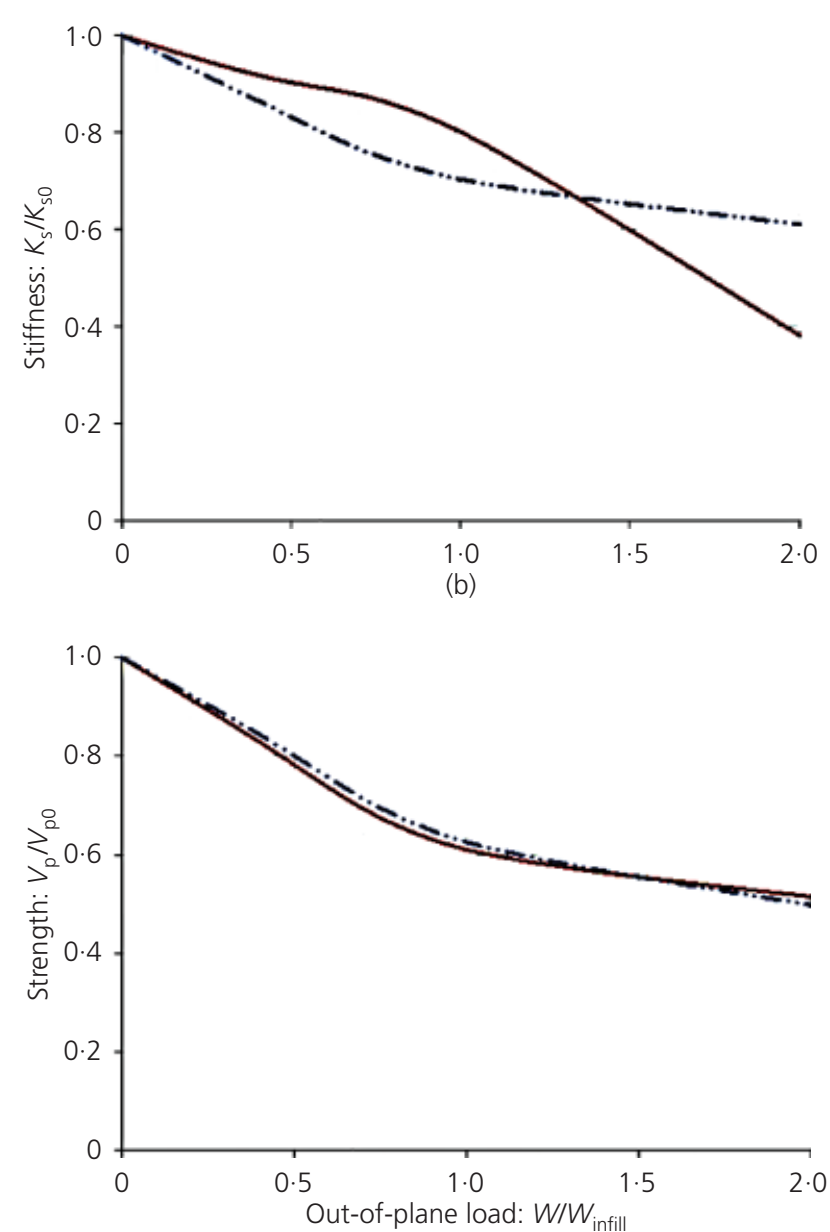

(d) dynamic cyclic loading. The global dynamic behaviour of twostorey, two-bay infilled RC frame structures with two different infill configurations (full infills and door-opening infills) under seismic excitation was thus investigated. The prototype structure was designed to resist earthquakes with a PGA of $0 \cdot 15 \boldsymbol{g}$ and detailed to obtain moderate displacement ductility. The infill panels considered were composed of $600 \times 300 \times 125 \mathrm{~mm}$ masonry units and $10-\mathrm{mm}$-thick mortar joints. The material properties adopted for the infills were similar to those described in Section 3.

\subsection{Non-linear response history analysis}

The seismic performance of the infilled frame structures was investigated by non-linear response history analysis with four realistic earthquakes of different intensity levels. The earthquake records adopted for this analysis were

1979 El-Centro 1140-component at USGS station 5056 $(\mathrm{PGA}=0 \cdot 14 \boldsymbol{g})$
1987 Superstition-Hill 225-component at USGS station 5051 $(\mathrm{PGA}=0.46 \mathrm{~g})$

- 1995 Kobe 000-component at station Takatori $(\mathrm{PGA}=0 \cdot 61 \mathrm{~g}$ )

- 1999 Chi-Chi EW-component at station CHY080

$(\mathrm{PGA}=0 \cdot 96 \mathrm{~g})$.

Elastic response spectra of the four ground motion histories are shown in Figure 9. The 1979 El-Centro and the 1999 Chi-Chi ground motions can be considered as fortification and rare earthquakes with 475-year and 2436-year return periods, respectively, which would be experienced by the prototype RC frame structure.

Due to the highly non-linear nature of the simulation problem (which involves non-linear material responses, complicated and evolving constraints and contacts among components and nonlinear geometric effects), the response history analysis employed an explicit central-difference integration scheme with a time increment of $1^{-7} \mathrm{~s}$, while double-precision numbers were used in the analysis to retain sufficient precision. 

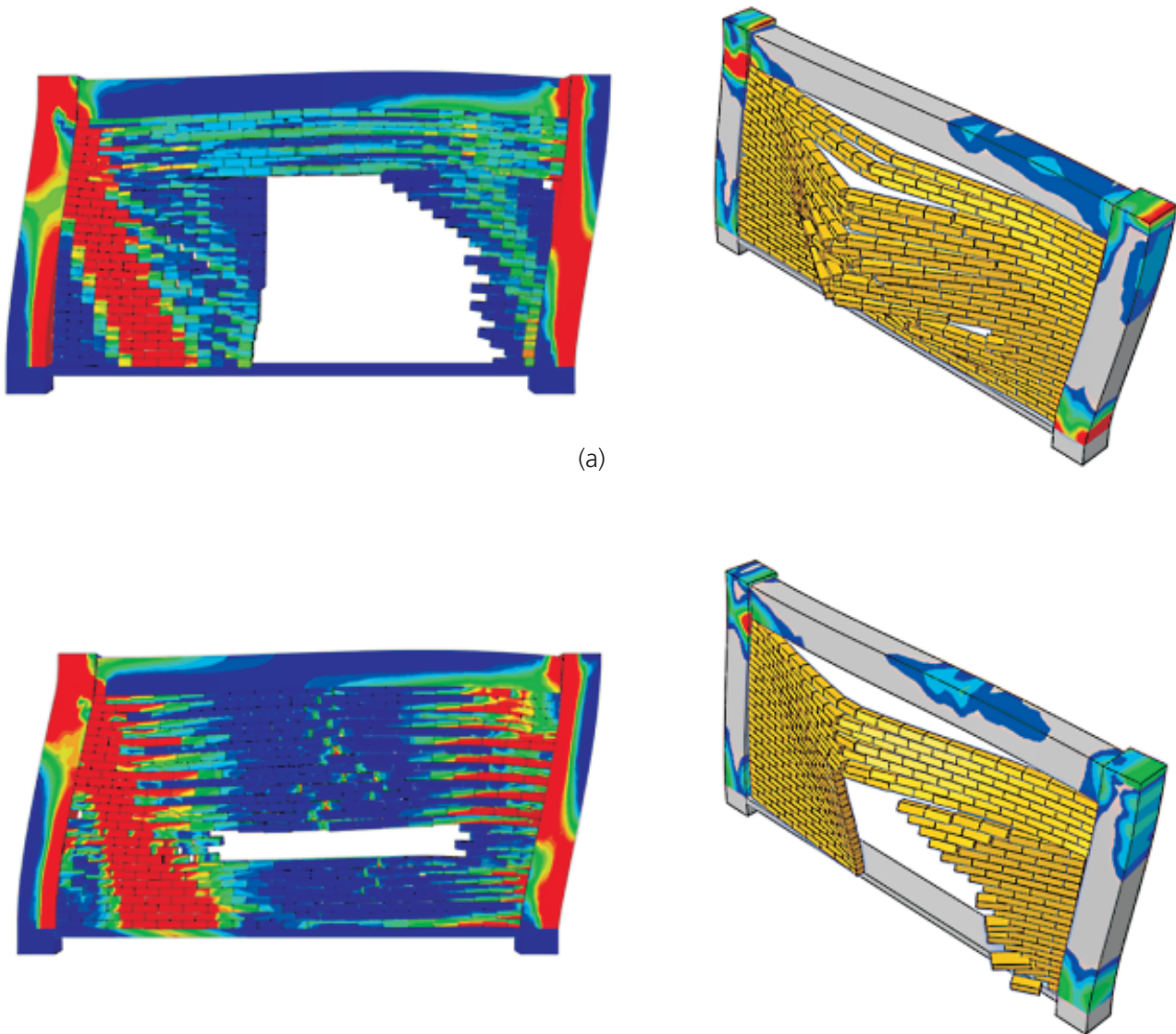

(b)

Figure 8. Ultimate stress transfer mechanisms and failure modes of (a) fully infilled frame and (b) infilled frame with door opening under combined in-plane and out-of-plane loads $\left(2 W_{\mathrm{m}}\right)$

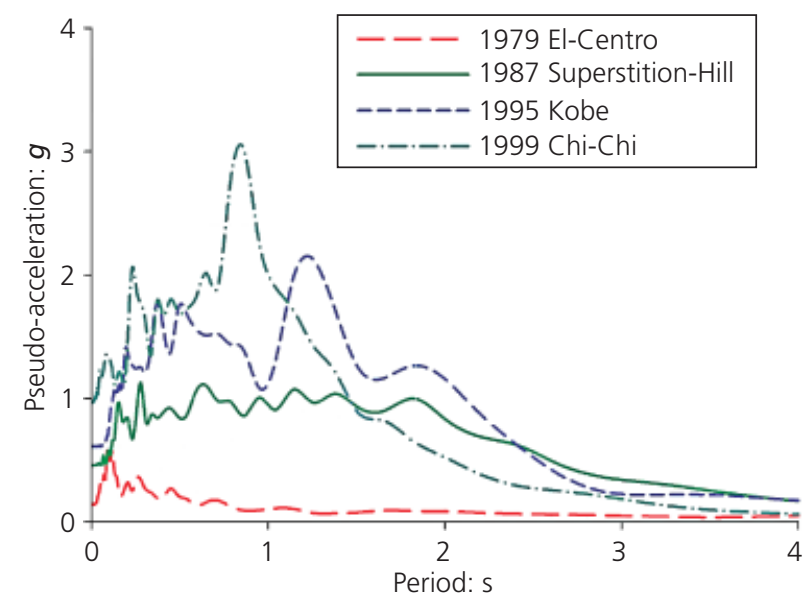

Figure 9. Elastic response spectra of ground motion histories

\subsection{Dynamic responses and seismic behaviour}

Subjected to the four ground motions, the resulting hysteresis loops of the prototype structures are plotted in Figure 10. The incurred deformation shapes and damage distributions of the structures are found to be similar under the strong ground motions and, as an example, contour plots of the developed inelastic strain on the structures under the Chi-Chi earthquake are shown in Figure 11. The fully infilled frame exhibits a localised damage pattern, and pinching and slip-lock phenomenon in the hysteresis loops under different earthquake excitations lead to a certain degree of strength and stiffness degradation. On the other hand, the first-storey columns of the fully infilled frame suffer much more severe damage than those of the second storey.

Figure 11 shows the force transfer mechanisms and failure modes of infilled frames under the Chi-Chi earthquake. It can be seen that infills at the first storey would experience larger seismic forces than those at the upper storey. Serious strain or deformation localisation in structural members of the first storey would then be promoted by the brittle cracking behaviour and the associated stress redistribution of infills. Such localised deformation in the structural members is hardly accommodated by the original frame design method, which does not consider the effect of infills on the frame structure, and serious and localised damage is thus incurred. 

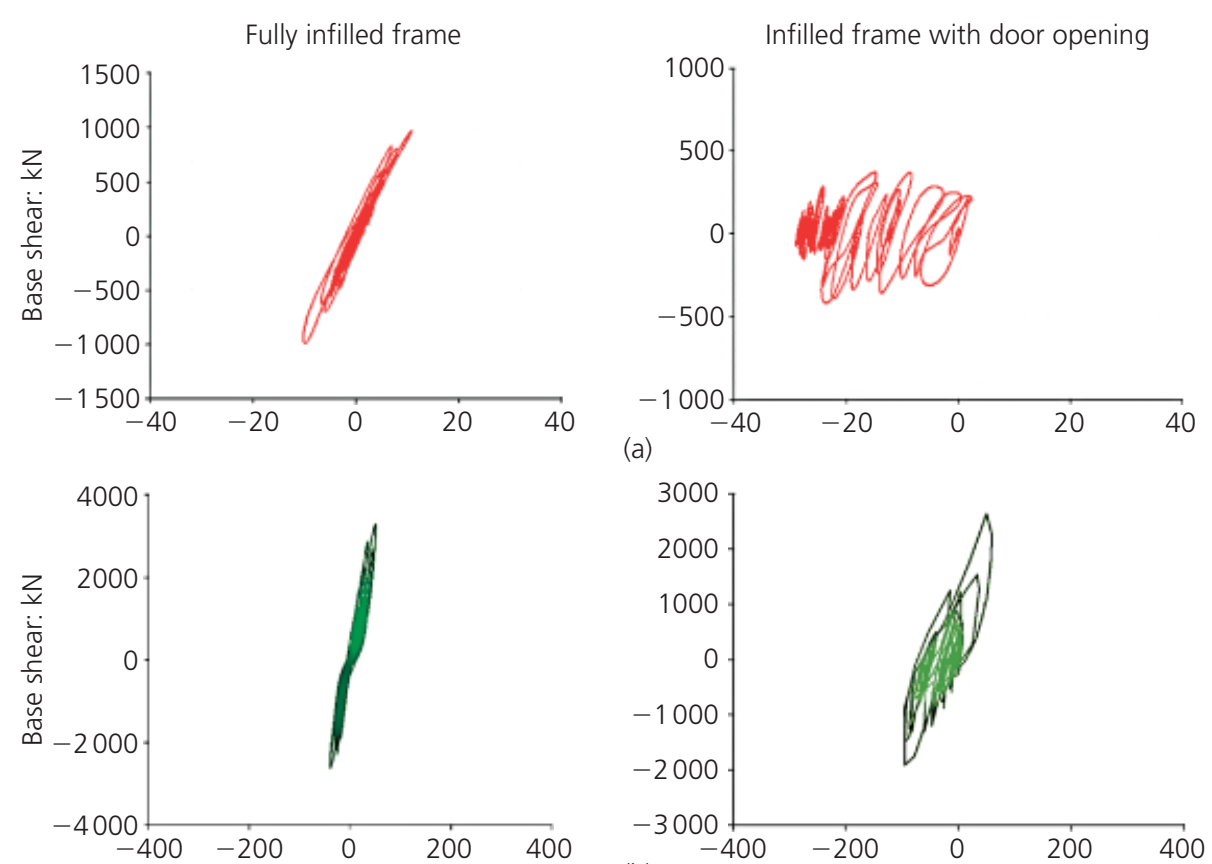

(a)
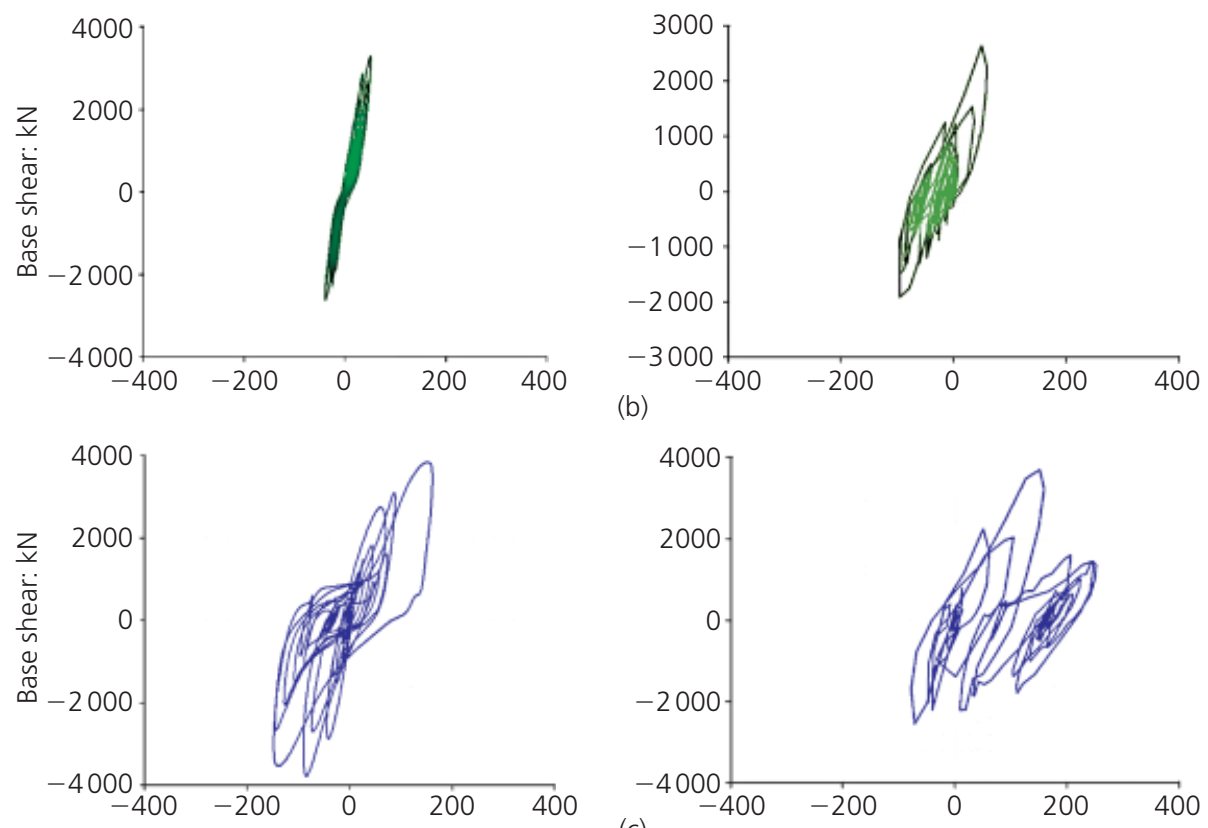

(b)
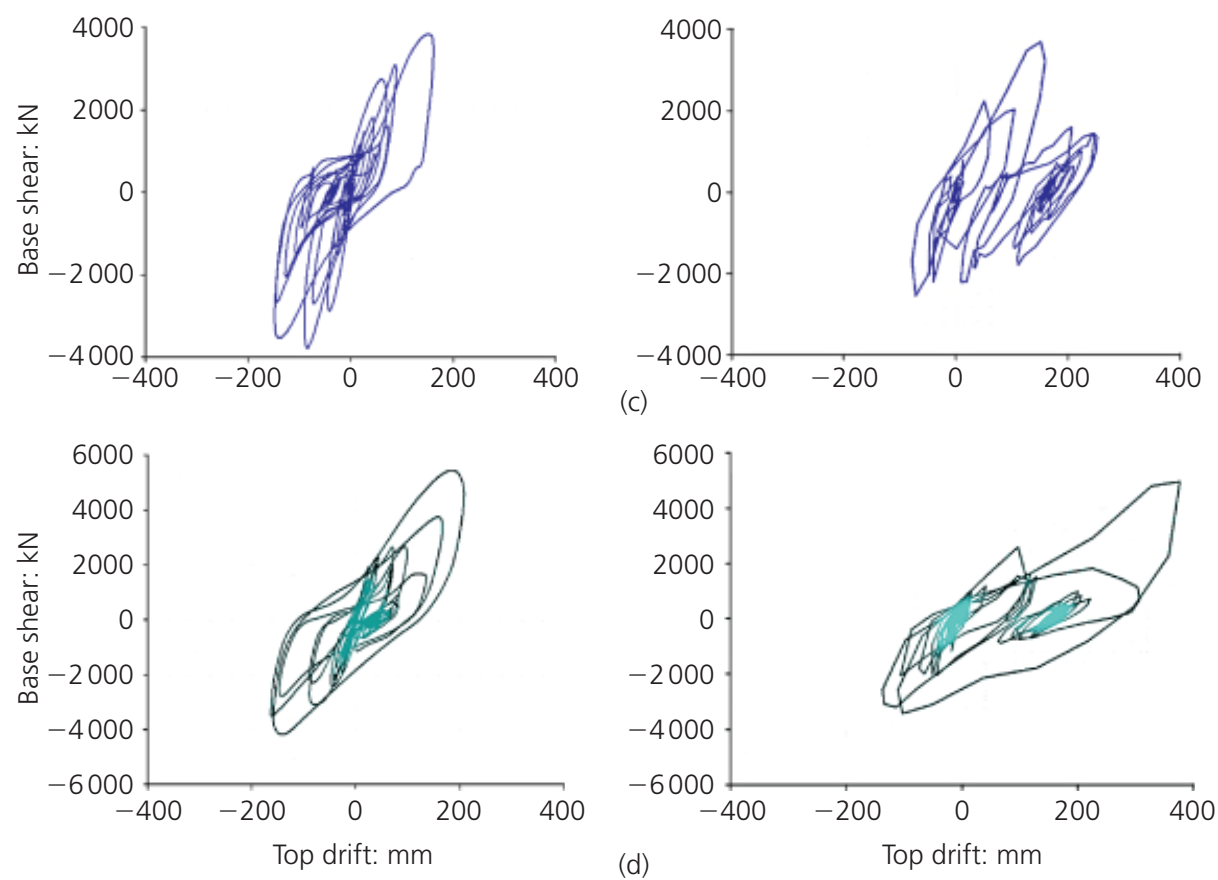

Figure 10. Hysteresis loops of infilled frame structures:

(a)1979 El-Centro; (b) 1987 Superstition-Hill; (c) 1995 Kobe;

(d) 1999 Chi-Chi

Furthermore, while plastic hinges cannot be formed in some of the beam ends, some do occur in unexpected locations, for instance near the middle of the top beams, in the frame, which also resulted in the bracing action (Figures 11(c) and 11(d)) provided by infills. Since the frame is designed as a typical ductile frame and only the member ends are confined with stirrups, the formation of plastic hinges at the unconfined regions would impair the ductility of the structure.

In infilled frame structures with door openings, the openings weaken the bracing action of infills to the bounding frame. The incurred base shear is reduced by $20 \%$ to $50 \%$ of that experienced 
Engineering and Computational Mechanics Volume 166 Issue EM4
Simulations of masonry-infilled reinforced concrete frame failure

Kuang and Yuen

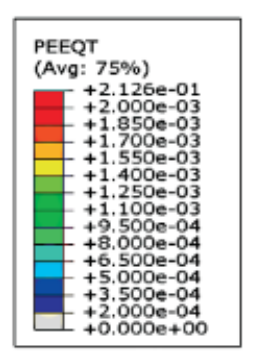

Fully infilled frame

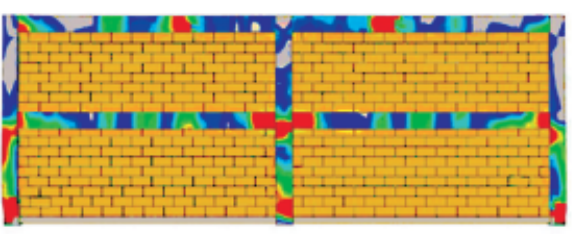

(a)
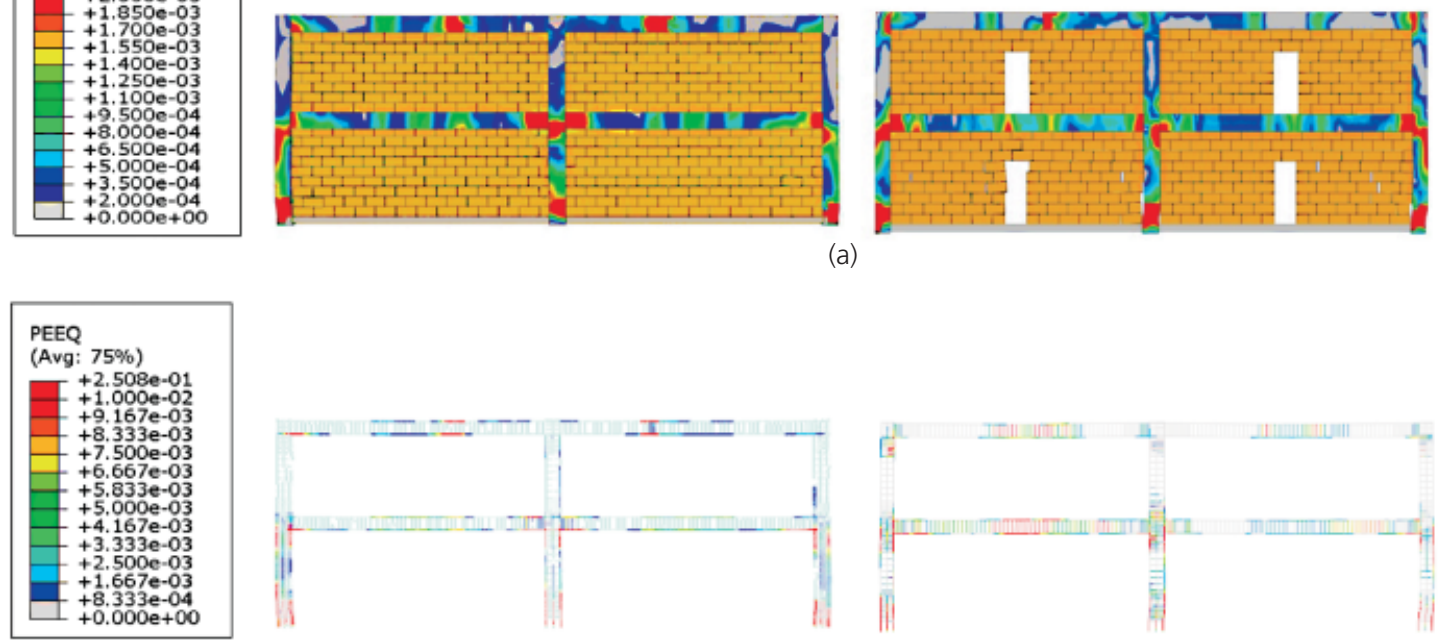

(b)
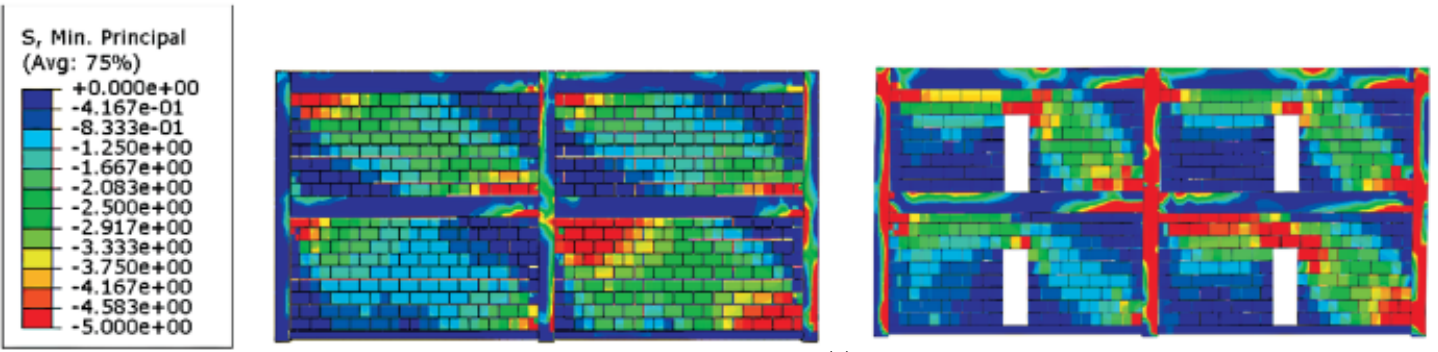

(c)
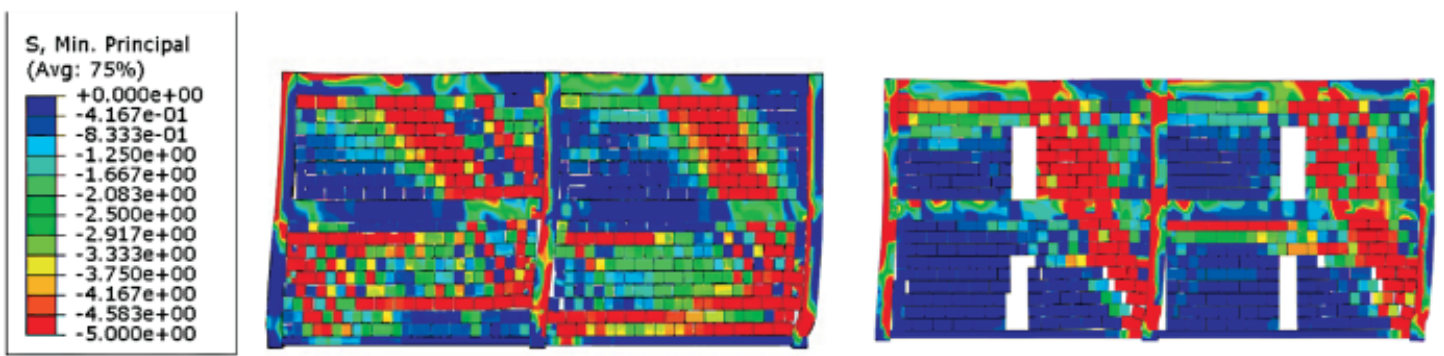

(d)
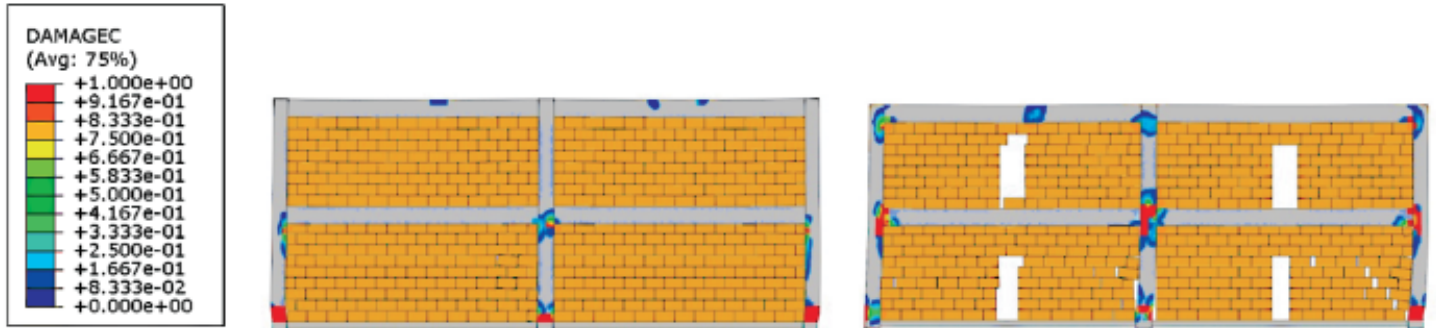

(e)

Figure 11. Force transfer mechanisms and failure modes of infilled frames under the Chi-Chi earthquake. (a) Crack strain distribution (at peak response). (b) Plastic strain distribution (at peak response) in steel reinforcement. (c) Force transfer mechanisms before major cracking. (d) Force transfer mechanisms after major cracking.

(e) Ultimate compressive damage distribution in concrete frame 
by the fully infilled frames. Figures 11 (a) and 11(b) indicate that the structures show rather asymmetrical damage patterns: the right-most columns suffer much more severe damage than the leftmost columns, but the reverse damage distribution can be seen in the beams (i.e. more damage is inflicted in the left-most beams).

The damage in infilled frame structures with door openings is apparently more severe than in the fully infilled frames, or more precisely speaking, the damage distribution is considerably more asymmetric. This is because the initially symmetric lateral force transfer mechanisms are destroyed by the ratchetting effect. The infills founded on the floors in the 'door' structures are not horizontally continuous due to the introduction of door openings, resulting in unrestrained sliding of infill panels. The sliding of infill panels leads to strong variations in the lateral force transfer mechanisms, as well as the resulting drifts and hysteresis loops, of the structures under loadings acting from the two opposite directions.

\section{Conclusions}

The discrete approach with damage-based cohesive crack representation for mortar joints employs a surface-based interaction modelling technique to simulate the interfacial traction-separation behaviour between contacting surfaces of masonry units. This approach is able to simulate the mixed modes of fracture, crack propagation, post-fracture behaviour, and finite sliding and separation of the bonded surfaces.

The applicability of the modelling approach for masonry and infilled frame structures subjected to different loading patterns was checked by performing computational simulations with the proposed model and verifying the results against experimental results. The simulations agreed very well with the experimental results of both in-plane and out-of-plane loading tests. The realistic failure modes and load-deformation behaviour of the masonry-infilled frame structures were successfully captured and reproduced by the discrete modelling method.

Use of the verified modelling technique to study the failure mechanisms and non-linear behaviour of infilled frame structures under the interaction of in-plane and out-of-plane loads and seismic excitation demonstrated the wide variety of applications of the model in solving non-linear and complex structural analysis problems of masonry structures and infilled frame structures.

\section{Acknowledgement}

The support of the Hong Kong Research Grant Council under grant number 614011 is gratefully acknowledged.

\section{REFERENCES}

Abaqus (2010) ABAQUS Theory Manual. Abaqus, Providence, RI, USA.

Angel R, Abrams D, Shapiro D, Uzaeski J and Webster M (1994) Behaviour of Reinforced Concrete Frames with Masonry
Infills. University of Illinois at Urbana-Champaign, Champaign, IL, USA, Report UILU-ENG-94-2005.

Bažant ZP and Pfeiffer PA (1986) Shear fracture tests of concrete. Materials and Structures 19(2): 111-121.

Benzeggagh ML and Kenane M (1996) Measurement of mixedmode delamination fracture toughness of unidirectional glass/epoxy composites with mixed-mode bending apparatus. Composites Science and Technology 56(4): 439449.

Crisafulli FJ and Carr AJ (2007) Proposed macro-model for the analysis of infilled frame structures. Bulletin of the New Zealand Society for Earthquake Engineering 40(2): 69-77.

Davies J (1995) Study of shear fracture in mortar specimens. Cement and Concrete Research 25(5): 1031-1042.

Hashemi A and Mosalam KM (2007) Seismic Evaluation of Reinforced Concrete Buildings Including Effects of Masonry Infill Walls. PEER Center, Berkeley, CA, USA, Report 2007/ 100.

Hsu TC and Mansour M (2005) Behavior of reinforced concrete elements under cyclic shear. II: Theoretical model. Journal of Structural Engineering ASCE 131(1): 54-65.

Kuang JS and Yuen YP (2010) Effect of out-of-plane loading on in-plane behaviour of unreinforced infilled RC frames. Proceedings of 13th International Conference on Computing in Civil and Building Engineering, Nottingham, UK, pp. 513514.

Lubliner J, Oliver J, Oller S and Oñate E (1989) A plastic-damage model for concrete. International Journal of Solids and Structures 25(3): 229-326.

Mehrabi AB and Shing PB (1997) Finite element modeling of masonry-infilled RC frames. Journal of Structural Engineering ASCE 123(5): 604-613.

Moghaddam HA and Dowling PJ (1987) The State of The Art in Infilled Frames. Imperial College of Science and Technology, London, UK, Report ESEE 87-2.

Park R (1989) Evaluation of ductility of structures and structural assemblages from laboratory testing. Bulletin of The New Zealand National Society for Earthquake Engineering 22(3): 155-166.

Paulay T and Priestley MJN (1992) Seismic Design of Reinforced Concrete and Masonry Buildings. Wiley, New York, NY, USA.

Raijmakers TMJ and Vermltfoort ATh (1992) Deformation Controlled Meso Shear Tests on Masonry Piers. TNO-BOUW/ TU Eindhoven, Eindhoven, the Netherlands, Report B-921156.

Rots JG (1997) Structural Masonry: An Experimental/Numerical Basis for Practical Design Rules. Balkema, Rotterdam, the Netherlands.

Sloan SW, Abbo AJ and Sheng D (2001) Refined explicit integration of elastoplastic models with automatic error control. Engineering Computations 18(1/2): 121-154.

Van der Pluijm R (1993) Shear behaviour of bed joints. Proceedings of 6th North American Masonry Conference, Philadelphia, PA, USA, pp. 125-136. 
Yuen YP (2012) Seismic Performance and Failure Mechanisms of Infilled RC Frames: Numerical Simulation and Theoretical Modelling. PhD thesis, The Hong Kong University of Science and Technology, Hong Kong.
Yuen YP and Kuang JS (2012) Nonlinear responses and failure of infilled RC frame structures under biaxial seismic excitation. Proceedings of 15th World Conference on Earthquake Engineering, Lisbon, Portugal, paper 1342.

\section{WHAT DO YOU THINK?}

To discuss this paper, please email up to 500 words to the editor at journals@ice.org.uk. Your contribution will be forwarded to the author(s) for a reply and, if considered appropriate by the editorial panel, will be published as a discussion in a future issue of the journal.

Proceedings journals rely entirely on contributions sent in by civil engineering professionals, academics and students. Papers should be 2000-5000 words long (briefing papers should be 1000-2000 words long), with adequate illustrations and references. You can submit your paper online via www.icevirtuallibrary.com/content/journals, where you will also find detailed author guidelines. 